\title{
ТЕОРЕТИЧЕСКИЕ ОСНОВЫ ИНФОРМАТИКИ В КОНТЕКСТЕ ИНФОРМАЦИОННЫХ ПОТРЕБНОСТЕЙ КОЛЛЕКТИВНЫХ И ИНДИВИДУАЛЬНЫХ ПОЛЬЗОВАТЕЛЕЙ
}

\section{THEORETICAL FOUNDATIONS OF COMPUTER SCIENCE IN THE CONTEXT OF THE INFORMATION NEEDS OF COLLECTIVE AND INDIVIDUAL USERS \\ E. Belyakova}

Summary. The article is devoted to the generalization of scientific views and approaches of various scientists to understanding the essence of the theoretical foundations of computer science. The study concluded that it is necessary to separate similar and synonymized concepts of "theoretical informatics" and "theoretical foundations of informatics", since the latter term is broader. In the conclusions of the article, the author's own definition of the concept of "theoretical foundations of computer science" is formulated.

Keywords: informatics, informatics theory, information needs of society, theoretical informatics, theoretical foundations of informatics.
A ктуальность темы исследования обусловлена стремительным развитием информационных интернет-технологий (ИТ), что ставит на первое место необходимость в получении умений и навыков в области теоретических основ информатики. Немаловажную роль при этом играет и то, что потребность в ИТ-специалистах на современном российским рынке труда имеет положительную динамику, то есть спрос на данную категорию сотрудников не просто стабилен, но и имеет благоприятные перспективы роста [1]. В связи с этим важно обладать определенным набором знаний в области информационных технологий, в основе которых, как в принципе и в основе любых других областей наук, лежит теория.

Когда речь идет о теоретических основах информатики, то в данном случае, как справедливо отмечает О.Е. Лебедев, следует иметь ввиду комплекс научно-обоснованных позиций, взглядов, точек зрения, логически подкрепленных определенными доводами, суждениями и выявленными закономерностями [4].
Белякова Екатерина Владимировна

Аспирант, ФГБОУ ВО «Московский технологический университет (МИРЭА)», г. Москва; старший преподаватель, ФГБОУ ВО «Государственный университет по землеустройству», г. Москва ekaterinaw@list.ru

Аннотация. Статья посвящена обобщению научных взглядов и подходов различных ученых к пониманию сути теоретических основ информатики. В рамках исследования сделан вывод 0 необходимости разделения схожих и синонимизируемых понятий «теоретическая информатика» и «теоретические основы информатики», поскольку последний термин является более широким. В выводах статьи сформулировано собственное авторское определение понятию «теоретические основы информатики».

Ключевые слова: информатика, теория информатики, информационные потребности общества, теоретическая информатика, теоретические основы информатики.
Если обратиться к научным взглядам Н.В.Липчиу, то можно увидеть, что в основе любой теоретической основы должны лежать доказанные научные теории, обоснованные концепции, логические умозаключения, исторически сложившиеся взгляды, идеи, положения ученых и исследователей в конкретной области знаний [5, с. 23].

Следовательно, применительно к теоретическим основам информатики, в данную область знаний можно отнести все без исключения понятия, относящиеся к информационным технологиям (например, такие термины, как информация, алгоритм, автоматизация, программа, кодирование, компьютер и многие другие), весь комплекс и эволюцию знаний в данной сфере, различные теории (например, речь может идти о теории информации Шеннона, либо о достаточно известной теории кодирования, а также необходимой для понимания сути информационно-технологических процессов теории алгоритмов и других не менее важных теорий [8, с. 2]), выражения и мысли ученых, представленных на бумажных и электронных носителях. 
Теоретические подходы к исследованию информатики отображаются в научных трудах известных деятелей в данной сфере, причем уже довольно давно. Всесторонне изучение теоретических основ информатики началось, в частности, с исследования самого понятия информации (А. Урсул [9]).

В отечественной литературе термин «теоретические основы информатики» был впервые введен в конце XX века исследователем Б. Наумововым [7], посвятившим большое количество своих научных трудов изучению процессов автоматизации с теоретической и практической точки зрения. Данный термин рассматривался ученым как часть теоретической информатики, но точного определения ни тому, ни другому понятию профессором сформулировано так и не было.

Интересно, что определение понятию «теоретические основы информатики» встретить достаточно проблематично, хотя данным словосочетанием называются научные труды, учебные пособия, статьи, то есть термин встречается достаточно часто.

Более определенным является понятие «теоретическая информатика». К примеру, с точки зрения В.Б. Голубковой теоретическая информатика является той областью знаний, в рамках которой происходит теоретическое осмысление и эмпирическое рассмотрение всех аспектов человеческой деятельности, так или иначе связанных с процессами автоматизации информационных систем. С позиции названного ученого, если речь идет о теоретической информатике, то в данном случае следует иметь ввиду исследование теоретических аспектов теории проектирования автоматизированных систем, процессов обработки, распределения и использования различных потоков информации с помощью компьютеров и других технических систем, а также изучение всех понятий, связанных с историей, эволюцией, современным и будущим развитием информатики, её взаимодействием с человеком и окружающей действительностью [2, с. 7].

С позиции И.В. Черпакова, теоретическая информатика охватывает области знаний, исследующие теорию информации, математическую логику и теорию алгоритмов [10, с. 12]. Данное определение, на наш взгляд, является достаточно узким, поскольку абстрактная сторона информатики как науки представлена гораздо более широким набором теоретических исследований. Так, к примеру, данное определение не рассматривает теорию проектирования и ряд других важный подотраслей информатики.

В целом, как видится, целесообразно было бы разделить понятия «теоретическая информатика» и «те- оретические основы информатики», несмотря на их синонимизационную схожесть. Обосновать данное суждение можно тем, что теоретические основы информатики могут включать в себя и теоретическую информатику, и изучение теоретических аспектов прикладной информатики, в то время как в трудах ученых два последних термина ставятся совершенно противоположными друг другу [10, с. 12]. Некоторые авторы и вовсе рассматривают теоретическую информатику, отделяя её от общей информатики [6, с. 5], хотя последняя также имеет определенные теоретические основы.

В связи с этим целесообразно было бы дать четкое единое для понимания всеми исследователями и учеными определение термину «теоретические основы информатики».

С позиции А.Г. Ермолаевой, возможность к глубокому, профессионально-ориентированному, организованному и качественному преподнесению теоретических основ информатики лежит в необходимости ориентации педагогического процесса на философские взгляды (мировоззренческий подход к познанию системно-информационной картины мира), на ключевые аспекты современной филологии (в частности это может касаться, к примеру, освоения теоретических аспектов пользования текстовыми редакторами, системами искусственного интеллекта), а также на теорию изобразительного искусства и теоретические основы графики (осмысление обучающимися теоретических аспектов пользования профильными редакторами, мультимедийными комплексами и т.д.) [3, с. 467].

Таким образом, исследование теоретических основ информатики позволяет сделать ряд следующих выводов.

Во-первых, следует различать понятия «теоретическая информатика» и «теоретические основы информатики».

Во-вторых, исследование различных позиций и взглядов ученых к определению самого термина «теоретические основы информатики» позволяет констатировать факт отсутствия его единого понимания.

В связи с этим сформулируем собственное авторское определение рассматриваемому понятию: теоретические основы информатики - это совокупность понятий, позиций, взглядов, точек зрения, концепций, определений, теорий, выражений и мыслей в области различных подотраслей информатики, логически подкрепленных обоснованными умозаключениями, выводами, доводами, суждениями и выявленными закономерностями. 


\section{ЛИТЕРАТУРА}

1. В России резко вырос спрос на дорогих ИТ-специалистов [Электронный ресурс]. - Режим доступа: https://www.cnews.ru/news/top/2020-01-24_ spros_na_dorogih_itspetsialistov (дата обращения: 19.02.2021).

2. Голубкова В.Б. Вопросы теоретической и прикладной информатики: учебное пособие / В.Б. Голубкова, А.И. Брагинский. 一 М.: МАДИ, 2019.— 72 с.

3. Ермолаева А.Г. Формирование теории и методик преподавания информатики как инструмент повышения информационной грамотности / А.Г. Ермолаева, Н.С. Чистякова // Интеграция наук, 2018.— № 8.— С. 466-467.

4. Лебедев 0.Е Теоретические основы педагогического целеполагания в системе образования: дисс. док. пед. наук [Электронный ресурс].- Режим доступа: https://search.rsl.ru/ru/record/01008041932 (дата обращения: 19.02.2021)

5. Липчиу Н.В. Методология научного исследования: учебное пособие / Н.В. Липчиу, К.И. Липчиу. — Краснодар: КубГАУ, 2013. — 290 с.

6. Майоров А.А. Общая и теоретическая информатика: учебное пособие / А.А. Майоров, В.П. Седякин.— М.: МИИГАиК, 2017. - 128 с.

7. Наумов Б.Н. Информатика и компьютерная грамотность [Электронный ресурс]. - Режим доступа: https://www.elibrary.ru/item.asp?id=27309131 (дата обращения: 19.02.2021).

8. Стариченко Б.Е. Теоретические основы информатики: учебник для вузов, 3-е изд. перераб. и доп. / Б.Е. Стариченко. — М.: ГЛТ, 2016. — 400 c.

9. Урсул А.Д. Природа информации [Электронный ресурс]. - Режим доступа: https://cyberleninka.ru/article/n/priroda-informatsii-rets-na-kn-ursul-a-dpriroda-informatsii-filosofskiy-ocherk (дата обращения: 19.02.2021).

10. Черпаков И.В. Теоретические основы информатики: учебник и практикум для академического бакалавриата / И.В. Черпаков.— М.: Юрайт, 2017.353 c.

(c) Белякова Екатерина Владимировна ( ekaterinaw@list.ru).

Журнал «Современная наука: актуальные проблемы теории и практики»

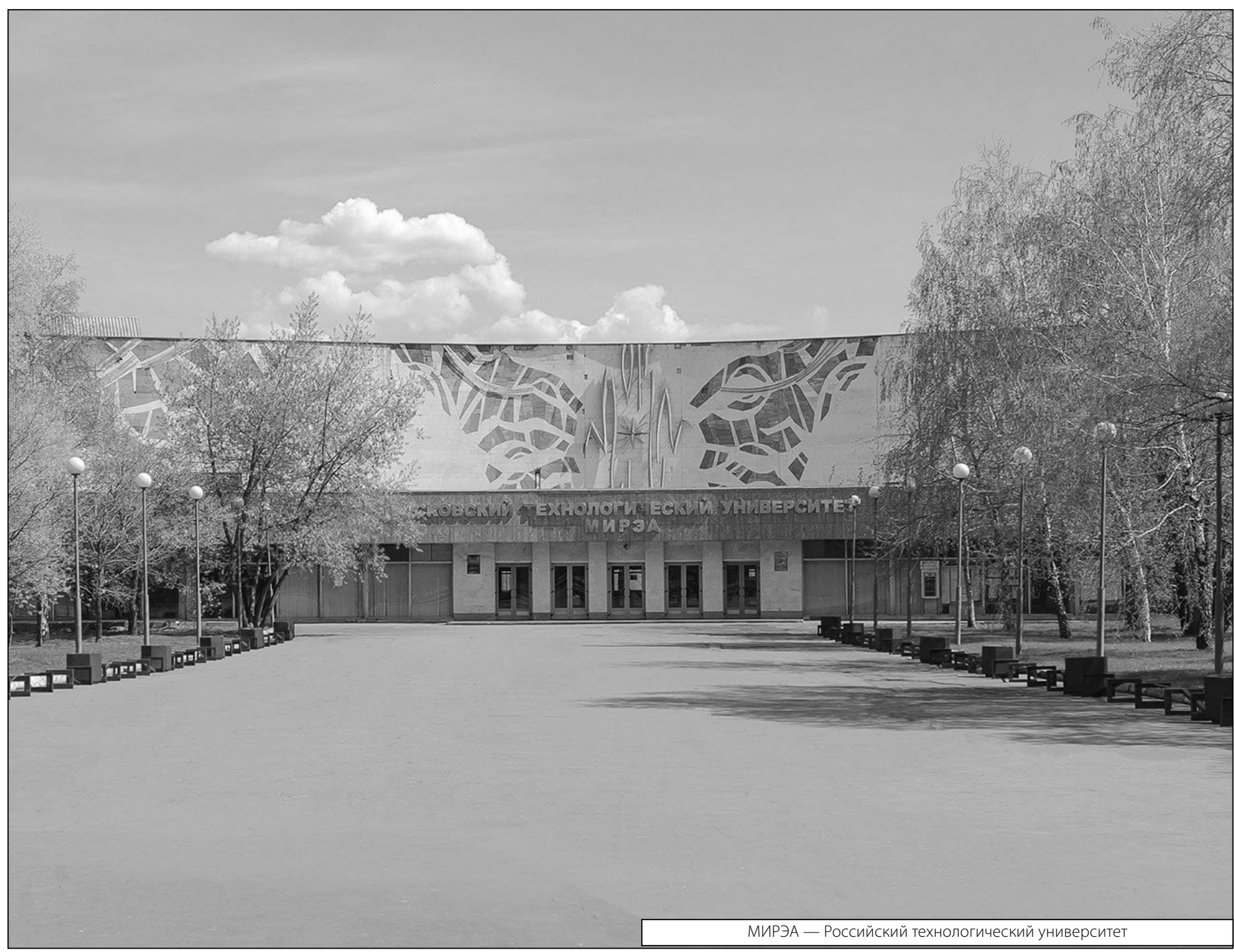

